\title{
Frágil culpabilidad. El conflicto entre arrogancia moral y sabiduría trágica en Eurípides*
}

\author{
Fragile guiltiness. The conflict between moral arrogance and \\ tragic wisdom in Euripides.
}

Recibido: 23 de agosto de 2012 - Revisado: 08 de septiembre de 2012 - Aceptado: 09 de octubre de 2012

John Fredy Lenis Castaño**

\section{Resumen}

En Eurípides se halla la tesis del carácter humano de la culpa y el castigo, convirtiendo la responsabilidad en un asunto inmanente a la vida de los hombres a pesar de las creencias religiosas. En este sentido, la ley, las pasiones humanas, la racionalidad y la fe entran en una tensión que no ha dejado de darse a pesar de la renovación moral de la modernidad. Este artículo se estructurará siguiendo algunos temas morales fundamentales de varias tragedias de dicho pensador desde una perspectiva principalmente genealógica y hermenéutica, haciendo un análisis intra e intertextual que permita poner en consideración la importancia de la sabiduría trágica para el aleccionamiento de una conciencia moral falible e histórica.

\section{Palabras clave}

Complejidad existencial, culpabilidad, sabiduría trágica, arrogancia moral, dionisismo, Eurípides.

\begin{abstract}
In Euripides the thesis of the human character of fault and punishment is found, turning the responsibility into an immanent subject to men's life in spite of the religious beliefs. In this sense the law, the human passions, rationality and faith get into a tension that has been continuing, taking place regardless of the moral renewal of modernity. This article will be structured following some fundamental moral themes of several of the aforementioned thinker's tragedies from a mainly genealogical and hermeneutical perspective, making an intra- and inter-textual analysis that allows to put into consideration the importance of the tragic wisdom for the instruction of a moral fallible and historic conscience.
\end{abstract}

\section{Key Words}

Existential complexity, guiltiness, tragic wisdom, moral arrogance, dionisism, Euripides.

\footnotetext{
"Este artículo proviene de la investigación doctoral titulada 'Tribulaciones de la consciencia. Culpabilidad y subjetivación a partir de Michel Foucault', la cual está siendo desarrollada en el marco del doctorado en Filosofía del Instituto de Filosofía de la Universidad de Antioquia. ** Profesor del Instituto de Filosofía de la Universidad de Antioquia. Licenciado, magíster y candidato a doctor en Filosofía de la misma institución. Correo electrónico: johnlenisc@gmail.com
} 


\section{Introducción}

Algunos trabajos fenomenológicos sobre la culpabilidad como los de Ricoeur (2004) y Jankélévitch (1987), o hermenéuticos como el de Pewzner (1999) permiten entender la culpa como una experiencia fundamentalmente simbólica, cultural y del orden del padecimiento subjetivo. Sin embargo, estas perspectivas dejan de lado la misma complejidad histórico-social de la culpabilización, su carácter profundamente intersubjetivo, social y material, así como los diferentes énfasis de la moralidad según las épocas, los intereses, las luchas de poder y los textos (Cf. Foucault, 1994, p. 372; 1994a, pp. 408-409). En este sentido, el trabajo en el que se inscribe el presente artículo, a saber, una investigación doctoral sobre culpabilidad y subjetivación a partir de Michel Foucault, busca precisar algunas características de la racionalidad culpabilizadora occidental en un horizonte principalmente genealógico-hermenéutico, lo cual quiere decir que se privilegia el análisis crítico e histórico de la culpabilidad con el fin de explicar cómo funciona — según distintos registros y discursos, prácticas y hábitos, intereses y poderes - la instrumentalización de la racionalidad culpabilizadora. Con esto se busca aportar un análisis menos ingenuo sobre la culpabilidad mostrando algunos peligros de sus usos así como algunas posibilidades de resistencia ética frente a las implicaciones de una moral alienante. En este contexto, la elaboración del presente artículo tiene como objetivo principal analizar algunas de las tesis más importantes de la antigüedad griega en torno a la experiencia moral de la culpabilización a partir de un autor que como Eurípides es uno de los primeros y más importantes críticos de la cultura occidental, toda vez que no solo se confrontó con una sociedad profundamente mítico-religiosa sino también con algunas dificultades del racionalismo moral, ubicándose así como uno de los primeros autores que exploraron la experiencia de la resistencia ética frente a la estigmatización culpabilizadora en medio de complejas situaciones culturales, morales y sociales. Ahora bien, en función de la extensión propia de un artículo de este tipo, nos concentraremos en algunas de sus principales tragedias para mostrar la hipótesis central de su concepción moral, a saber, el carácter humano y polémico de la responsabilidad, independientemente de los designios divinos y el conflicto del afán racionalista que consiste en darle primacía a la lógica deliberativa y conceptual en detrimento de la consideración de los aspectos emocionales de la existencia, las pasiones envueltas en diversas luchas de poder y los usos de las justificaciones morales en aras de los intereses individuales. Para ello procederemos a través de los siguientes apartados: (1) la lucha humana y agonal de la culpabilización, que permitirá precisar el horizonte principal de las tragedias de Eurípides, esto es, la tensión entre el racionalismo antiteológico y el reto que las pasiones, los intereses y las justificaciones humanas le plantean al racionalismo en el drama de la moral en situación; (2) el contexto normativo de la culpabilidad, cuyo tema central es el carácter convencional de las leyes humanas y la dimensión comunitaria de las exigencias recíprocas; (3) intersubjetividad, ley y juicio moral, que abordará la odisea en que se constituye el intento subjetivo de justificación en medio de las normas y las conminaciones provenientes de la alteridad y el peso de las acciones realizadas; (4) el moralista y la complejidad existencial, para poner de relieve tanto la fuerza del vínculo moral entre discurso y acción como la fragilidad de la certeza moral afincada en el sentimiento de la absoluta inocencia personal dada la presencia de lo involuntario, haciendo de todo rigorismo ético un cierto patetismo inconsciente de sus propias debilidades; (5) franqueza, valía moral y fragilidad del juicio condenatorio, que posibilitará la comprensión del carácter ontológico del juicio moral, esto es, sus connotaciones en la definición misma de la identidad a pesar de su concentración en la acción, así como el impacto emocional del drama moral; (6) sed de venganza y obnubilación del juicio, que permitirá, en estrecha continuidad con el apartado anterior, resaltar la turbiedad del juicio empecinado, la 
dimensión corporal del remordimiento y la dificultad de la realización de los juicios condenatorios; (7) conciencia moral y alteridad del exceso dionisíaco, el cual viene a resaltar la importancia de la "antimoral" dionisíaca para la formación de la conciencia moral, para su desapego de la arrogancia y el moralismo, para su refinamiento y matización a través de la escuela de la desposesión de sí, de su falibilidad, de la desmesura, de la alegría y del disfrute vital, de la praxis en contra de la hiperreflexión; para, finalmente, elaborar una conclusión general en torno al carácter muchas veces paradojal y falible de la conciencia moral, su no coincidencia consigo misma en los avatares de la relación ético-política y el reto que ello constituye. En este sentido, se hace enriquecedor volver a Eurípides y sus tragedias tejidas alrededor de esa naturaleza conflictual del hombre, su condición polémica y dionisíaca en la inmanencia terrenal ("sin dioses"), frágil y caótica que se levanta empero como símbolo de una existencia labrada en el ejercicio de sus propias fuerzas y dificultades.

\section{La lucha humana y agonal de la cul- pabilización}

Si el racionalismo - definido como "el predominio de la reflexión racional, en cuanto instrumento específicamente humano de desentrañar todos los problemas que conciernen a la naturaleza y al hombre" (Medina y López, 1991, p. 18) - puede afectar los valores tradicionales de una sociedad toda vez que lleva a cabo una crítica de ellos como una de sus tareas permanentes, y este es en gran medida el caso de Eurípides, algún tipo de culpabilidad, por su parte, parece sostenerse independientemente de la crítica a la moral tradicional. Y ello se debe a que esa compleja experiencia también saca su savia de una raigambre distinta a la veta religiosa: un marco jurídico positivo, unas reglas de juego que la misma sociedad se da, aparte de las creencias religiosas y míticas; con lo cual el mundo de los dioses deja de tener una importancia radical y absoluta para el mundo de los hombres. Sin embargo, si el racionalismo euripídeo funciona de cara a la religión, otro es el caso cuando se enfrenta con las pasiones propiamente humanas (p. 25). Ante estas, la razón muchas veces muestra su insuficiencia para regular la experiencia vital. Tratándose así de una culpa sin dios y envuelta en las luchas pasionales de los hombres. Como lo subrayan De Cuenca y García en la introducción a Orestes (1998, p. 169), las tragedias de Eurípides ahondan en el sinsentido de la existencia y los dramas humanos:

Mientras en la Orestía esquílea la presencia de los dioses es un factor constante, aquí solo se evoca la orden de Apolo que ha llevado al triste Orestes a un crimen cuyo sentido no acierta a disculpar su propia conciencia. El propio Apolo vendrá al final de la tragedia a exponer una explicación ambigua $\mathrm{y}$ poco convincente (p. 171).

La definición de responsabilidades se convierte, bajo esta óptica, en el intento a veces desesperado por darles un sentido a los acontecimientos y a las reacciones humanas. Por ello las tragedias de Eurípides no buscan moralizar, se convierten en la puesta en escena de la paradójica condición humana que, sin embargo, solo a partir de su debilidad ontológica puede hacer algo. En este sentido, la tragedia y la culpa hablan de la tensa situación de los seres humanos, a veces ángeles caídos y, otras, demonios sublevados. Tal vez lo trágico en Eurípides se enmarque precisamente en este fracaso de la razón dialéctica pues la racionalidad, en tanto trágica, se revela como autocrítica (de la razón), "esta salida batalladora del pensamiento humano, apoyado en sí mismo, hacia el caótico y peligroso terreno de las antinomias. Esto constituye precisamente lo trágico del poeta y del hombre Eurípides" (Lesky, 2001, p. 256). Para Medina y López la divinidad será cambiada por la Týche (1991, p. 35), ese azar que ya no tendrá el peso inapelable de la necesidad, con lo cual la explicación cabal de los acontecimientos humanos pierde en inteligibilidad. La complejidad 
de la vida humana desborda así cualquier perspectiva reductora que pretenda domesticarla según una lógica específica, reivindicando así su inagotable riqueza e imprevisibilidad. Siendo además la radicalización de la soledad del individuo ya no solo frente al mundo de los dioses, sino también frente al mundo social, cultural y político (p. 42), lo que le dará a Eurípides un pretexto privilegiado para mostrar el azaroso destino de los hombres.

Ningún héroe será ya objetivamente culpable, como acontecía en el teatro de Esquilo y Sófocles; ahora tendrá siempre alguna excusa, algún punto en el que apoyar su defensa, alguien o algo contra lo que quejarse, bien sea la arbitrariedad divina, la injusticia de un destino heredado o los vaivenes incontrolables de la fortuna (p. 44).

A partir de lo anterior, el artificio de la ley y la imputación puede aparecer con toda su fuerza. No es simplemente que la culpabilización desaparezca sino que ya no se cuenta con un referente (humano o divino) naturalmente objetivo para apoyar las señalizaciones y castigos. Dándose además una acentuación del carácter intersubjetivo de la acción, pues ya el individuo no es considerado como un sujeto moral de imputación claramente determinable, sino que la delimitación misma de la acción y su agente se problematiza. Y sin embargo no estamos ante un autor ateo:

Muchas veces el trágico se limita a mostrar su escepticismo ante las divinidades del mito, cual si fuese Protágoras; en otras ocasiones se perciben atisbos de una explicación del orden que debe regir el universo. Las críticas, por lo general, suelen ser duras, pero no nos autorizan a tildar a Eurípides de ateo, fama que le acompañó siempre en la antigüedad, sino de inquieto perseguidor de una imagen de lo divino más acorde con su esencia (p. 45).
En esta misma línea podría interpretarse la concepción de Bowra, pues si se dice que nuestro trágico consideraba a los dioses como "poderes ciegos e irracionales" (1948, pp. 8687 ) no hay que pensar que los expulsaba de su mundo de creencias, sino que los consideraba así: lejos de los propósitos humanos racionalmente planificados. Y si ello es así, mientras en Esquilo y Sófocles el castigo aparece como una consecuencia inevitable de la transgresión, en Eurípides aquel es merecido y dado ya no como destino sino como decisión. De este modo el tercer trágico aparece como un pensador menos tradicional, esto es, como un escritor que nos pone a pensar la culpa y el castigo como asuntos propiamente humanos, con lo cual el peso de la responsabilidad se convierte en elemento inmanente de la vida de los hombres.

Ahora bien, a pesar de que la etiología de la culpabilidad y el sufrimiento no la pone en la oposición consciente (o inconsciente) entre los hombres y los designios divinos, o en la asunción total de la fatalidad del destino; su piedra de toque la encuentra en "las pasiones desbordadas como el más formidable elemento de destrucción de la vida humana" (Medina y López, 1991, p. 53). Pero si los héroes de Eurípides son personajes totalmente contextualizados, su desenlace no dependerá únicamente de sus pasiones sino de la forma como estas interactúan con las pasiones de los demás, las circunstancias y el azar.

\section{El contexto normativo de la culpabilidad}

En El Cíclope (Eurípides, 1991) se puede ver ese carácter artificioso de la ley y la culpabilidad toda vez que es en un orden regido por las convenciones, las costumbres y las normas donde ello tiene sentido. En la vida natural del cíclope es innecesario todo ese dispositivo, él se lo dice a Odiseo: "En cuanto a los que establecieron las leyes, abigarrando la vida de los hombres, los invito a pudrirse. Yo no dejaré de hacer el bien a mi persona, ni de comerte a ti" (vv. 338-341) ${ }^{1}$. Licencia para el libre despliegue del egoísmo que se ancla, según Odiseo, en "el 
corazón y en la mente inaccesible de un hombre impío" (vv. 349-350) Esta insensibilidad frente a los mandatos y los ritos, las costumbres y las leyes, las jerarquías y las órdenes es el caldo de cultivo privilegiado para la inmoralidad y, con ello, la ausencia de sentimientos de culpa o remordimientos. El cíclope mismo es un monstruo y por ello un ser ajeno al abigarrado mundo legal de los humanos, pero paradójicamente símbolo de lo que el mundo humano también puede llegar a ser: despiadada batalla de egoísmos irreconciliables. La necesidad de instaurar la ley habla precisamente de una tendencia al mal realizable en la humanidad. No se trata simplemente de que el crimen o la producción de dolor sean ajenos a esta condición; propio de los seres humanos también es la posibilidad de efectuar el mal. La impunidad campearía la faz de la tierra sin leyes respecto a las cuales se definen la hýbris, la hamartía y la culpa. Esta última es entonces el resultado de un mundo regido por normas y sentimientos morales, y exhibe todo su relativismo cuando, al lado de la barbarie y la monstruosidad, se presenta como una noción banal. En suma, el cíclope de la tragedia no estaba lejos del cíclope de la epopeya. $\mathrm{Al}$ respecto, Castoriadis nos dice, refiriéndose a los cíclopes de La Odisea, "los Cíclopes no tienen thémistes, es decir, leyes; tampoco tienen agorái boulephoroi, es decir, asambleas deliberativas (...) Una colectividad que no posee esto es monstruosa" (2006, p. 106) y monstruosa no solo porque no tenían todo esto sino porque, al carecer de ello, también adolecían de conciencia moral y de culpa. No hay, pues, exigencia legítima de sentimientos morales donde no existe una comunidad religiosa, política o jurídica.

\section{Intersubjetividad, ley y juicio moral}

Medea (Eurípides, 1991), por el contrario, padece todas sus tribulaciones en medio del mundo de la ley, su dolor de esposa abandonada - Jasón la deja para casarse con la hija del rey Creonte- la pone en el trance de desear la muerte; y el coro, como mediador de la razón, le aconseja dejar correr la pena:
¿Has oído, oh Zeus, tierra y luz, qué canto de dolor entona la infeliz esposa? ¿Qué deseo del terrible lecho te tiene cogida, oh insensata? El fin de la muerte vendrá pronto. ¡No haga esta súplica! Si tu marido honra un nuevo lecho, responsabilidad suya es, no te irrites. Zeus te hará justicia en esto. No te consumas en exceso llorando a tu esposo (vv. 150-157).

La sagacidad de Creonte hace que la expulse temiendo que en represalia le haga algún mal a su hija (vv. 280 y ss.); y no estaba equivocado toda vez que, presa de su pasión y sin ninguna reflexión crítico-moral sobre sus planes, Medea maquina su venganza contra el rey Creonte, su hija y su infiel esposo; refiriéndose al corifeo le dice: "La desgracia me asedia por todas partes. ¿Quién lo negará? Pero esto no se quedará así, no lo creáis todavía. A los recién casados aún les acechan dificultades, y a los suegros no pequeñas pruebas" (vv. 364-367). La vileza del argumento de Jasón para abandonarla - “....lo hice con la intención de llevar una vida feliz y sin carecer de nada, sabiendo que al pobre todos le huyen, incluso sus amigos, y, además, para poder dar a mis hijos una educación digna de mi casa..." (vv. 559-563) nutre la impresión de que los planes de Medea están justificados. En efecto, no se pueden comparar los motivos de ambos: en una es el amor decepcionado y en el otro es la ambición desmedida de estatus. El escándalo por la ausencia de culpa en la maquinación macabra y fatal de su venganza se equilibra con la impresión que produce su situación de víctima; es más, no sin sufrimientos y sacrificios estabilizó su matrimonio. Es en el estado de un dolor profundo y sin apelaciones que ella decide su destino y el de los suyos, incluso es consciente del precio que tendrá que pagar por ello. Pero el exceso de su hýbris, al pretender darles muerte también a sus hijos con el fin de aumentar el desgarramiento de Jasón (v. 817), parece también anular la compensación y lo que alega como causa de su acto criminal, su dolor de esposa abandonada 
se muestra de este modo insuficiente e impertinente para justificar el asesinato de sus hijos. Estamos por ende ante el intento de explicar un crimen por otro, de transferir una esfera de imputación y castigo a otra y de confundir los motivos de una acción con los efectos de otra. El problema es que tanto Jasón como Medea subordinan la vida de sus hijos a la lógica de sus propósitos. El mismo coro le advierte a Medea:

¿Cómo la ciudad de los ríos sagrados, la tierra acogedora de los enemigos, te va a recibir a ti, la asesina de sus propios hijos, la impura entre las impuras? Piensa en el golpe que vas a dar a tus hijos, piensa en el crimen que afrontas (vv. 848-852).

No que piense en lo que Jasón le ha hecho sino en lo que ella va a hacer. Esta necesaria distinción entre actos y agentes se constituye en la inevitable circunscripción de atribuciones, imputaciones, castigos y penas del mundo moral. Al límite lo que el coro le reclama a Medea es "¿qué culpa tienen tus hijos para pagar por el daño que te ha hecho el esposo?". De hecho si no es el argumento del coro lo que disuade a Medea de su horrible acto, es el rostro de los hijos lo que la conmueve: “¡Ay, ay! ¿Por qué me miráis con vuestros ojos, hijos? ¿Por qué sonreís, como si fuese vuestra última sonrisa? ¡Ay, ay! ¿Qué voy a hacer? Mi corazón desfallece, cuando veo la brillante mirada de mis hijos" (vv. 1040-1044). Pero - según ella - ante el miedo a convertirse en hazmerreír de la ciudad por no vengarse de sus enemigos, vuelve y pone como firme propósito el sacrificio de su prole, aunque ello tampoco sirva para exculparla, pues ante el deber de amor de sangre la opinión de los demás poco debería contar. No se trata del clásico choque moral entre dos opciones igual de razonables como fruto de una sensata deliberación, aquí el dilema está en escoger entre el amor a sus hijos y el amor propio. El problema se profundiza aun más cuando, una vez enterada de que su proyecto de envenenamiento de su rival y de Creonte, el padre de esta, fue realizado, apela a la convicción de que, ante la inminente persecución, es mejor que sus hijos mueran por su propia mano que por la mano de otros (v. 1205 y ss.); para lo cual tiene que proponerse, empero, la idea de que no son carne de su carne (v. 1246). La lista de justificaciones para su tarea puede ampliarse, pero la conciencia de que son sus propios hijos inocentes los que va a sacrificar hace imposible limpiar la gravedad de la culpa en la que se apresta a incurrir. Finalmente, el dilema tampoco se resuelve en la discusión entre Jasón y Medea (v. 1320 y ss.): ambos se imputan la causa de la desgracia, y como debate sin síntesis final, la tragedia termina en la dispersión de acusaciones y culpas. La imposible enseñanza de este texto se convierte en la confrontación de dos dolores inconmensurables.

\section{EI moralista y la complejidad existencial}

En Hipólito (Eurípides, 1991) también está presente esa antropología moral expuesta en $\mathrm{Me}$ dea que permite ver la terrible tensión en que se encuentra inmersa la condición humana, jalonada por las pasiones y los valores que se yerguen como ley. Sin embargo, en Hipólito se muestran dos personajes enfrentados consigo mismos en la lucha por no sucumbir frente a deseos contrarios a sus principios. La fuerza del deseo del amor confrontada con el deseo de ser una fiel esposa pone a Fedra en la angustia de una lucha sin cuartel, su propio ser se ve desgarrado entre dos tendencias antagónicas y demandantes, lo cual se agudiza aún más con la conciencia que ella tiene de que no es suficiente con el conocimiento para evitar hacer el mal: "Sabemos y comprendemos lo que está bien, pero no lo ponemos en práctica" (vv. 380-382). Y si el mal no es un problema de ignorancia, la pasión que lleva a cometerlo desborda la mera dimensión intelectual (discursiva, argumentativa). Esta es usada por la atormentada esposa para anticipar la culpa de ceder a la tentación que siente por Hipólito y así se lo hace saber a la nodriza y al corifeo:

Esto, en verdad, es lo que me está matando, amigas, el temor de que un día sea sorprendida deshonrando a mi esposo y a los hijos que 
di a luz. ¡Ojalá puedan ellos, libres para hablar con franqueza y en la flor de la edad, habitar la ciudad ilustre de Atenas, gozando de buen nombre por causa de su madre! (vv. 419-424).

Y si bien Foucault enfatiza en este pasaje la importancia de la parresía (2004, pp. 56-58), no hay que pasar por alto que allí esta viene aunada a la ausencia de vergüenza, esto es, la posibilidad de decir la verdad porque no causa ninguna pena. El uso de la palabra está entonces subordinada a la limpieza moral, no es solo un decir teórico sino un hablar respaldado por la práctica de una acción sin mancha. La culpa entonces no solo inflige castigo físico en el imputado sino pesares discursivos a su descendencia. La palabra se convierte así en símbolo de rectitud moral garantizada por los actos. Incluso el combate que Fedra establece con la nodriza en el intento que hace esta para convencerla de ceder a su pasión de amor como cosa natural (Eurípides, Hipólito, 1991, v. 435 y ss.) es el reflejo de su propia lucha. Hipólito, por su parte y una vez se entera por boca de la nodriza del amor de Fedra hacia él, se muestra como el moralista inflexible que perjura hasta de sus propios amigos y allegados cuando estos obran de manera injusta: "Hipólito - He escupido. Ningún injusto es amigo mío. Nodriza - Perdona. Natural es que los hombres yerren, hijo" (vv. 614-615). Actitud propia de quien mira por encima del hombro las pasiones y vicisitudes humanas y considera el cumplimiento de la ley con la manía de una conciencia moral escrupulosa y aséptica ${ }^{2}$. Sin embargo, en el afán de convertirse en juez de Fedra se constituye en juez de sí mismo al reprochar la situación en que ha sido cogido. Su ansioso carácter inflexible lo atormenta al darse cuenta de que, como todos, está inmerso en la red de interacciones pasionales que tensiona permanentemente la vida moral. Para Fedra, el acontecimiento adquiere una gravedad de mayores proporciones al haberle sido contado a este juez implacable:

"Fedra (A la nodriza) — ¡Oh cúmulo de maldades y perdición de tus ami- gos, qué me has hecho! ¡Que Zeus, mi abuelo, te extirpe de raíz bajo el golpe de su rayo! No te dije — ¿no había adivinado tu intención? - que callaras aquello que ahora me ha traído la deshonra? Tú no te contuviste y, por ello, no moriré con gloria (vv. 682-687).

Este mal uso de la parresía sume a Fedra en el conflicto de verse descubierta. La circulación del saber se constituye en fuente de deshonra aunque no se haya realizado ningún contacto directo con Hipólito. El predicamento en que este se ve atrapado se debe precisamente al haber sido puesto en conocimiento de suscitar tales pasiones en una mujer casada. Él quizás hubiera preferido permanecer ignorante $\mathrm{y}$ al margen de tal entramado emocional para poderse sentir inocente. Más aún cuando las consecuencias no se hacen esperar; Teseo, esposo herido de Fedra, decide vengarse de Hipólito a pesar de que sea su propio hijo:

“...Le expulsaré de esta tierra y recibirá el golpe de uno de estos dos destinos: o Poseidón le enviará muerto a las moradas de Hades, por consideración a mis súplicas, o expulsado de esta tierra, errante por un país extranjero, soportará una vida miserable" (vv. 893-898).

El mismo desenlace fatal del hijo y ahora rival de Teseo, así como el descubrimiento de este del engaño usado por Fedra para aparecer inocente inculpando a Hipólito, sume al rey en el descorazonador sentimiento de no solo haber asesinado a su propio hijo por una acusación infundada, sino también de haberse dejado enceguecer por su propia pasión de esposo traicionado. Ártemis, la diosa que viene a anunciarle todo eso, se lo dictamina con una claridad meridiana:

Tú (....) te muestras como un malvado, pues no esperaste la confirmación y las palabras de los adivinos, ni a tener una prueba, ni concediste mayor tiempo a la indagación, sino que lanzaste la 
maldición contra tu hijo más rápido de lo que debías y lo mataste (vv. 13201324).

Su hýbris consistió por consiguiente en haberse dejado llevar por el vértigo de la pasión dolida sin poner el freno de la reflexión y el análisis objetivo de los hechos. Es el haber hipostasiado su propia subjetividad lastimada lo que lo sume ahora en el sufrimiento de no haber sabido escuchar ni mirar. Sin embargo la diosa, señalándole que Cipris (diosa del amor) fue protagonista en estos sucesos, que él actúo con desconocimiento y que su esposa se suicidó llevándose consigo la posibilidad de explicar lo que realmente había pasado, le dice que aún él puede ser perdonado (v. 1330 y ss.). Incluso por la misma conciencia rígida de Hipólito, este, agonizante y siendo instruido por la diosa Ártemis en el sentido de que es propio de los humanos equivocarse cuando los dioses no les ayudan a evitarlo, asume su destino excluyendo al padre de cualquier imputación y culpa (v. 1400 y ss.). La implacable moral de Hipólito se suaviza en la confrontación con una situación límite - accidente y conciencia de la muerte que se acerca- poniendo en entredicho cualquier seguridad moral de los que, como él, más convencidos estaban de la rigidez y cabal cumplimiento de las recompensas y méritos para inocentes y piadosos. Lo involuntario aqueja la condición humana y por ello la asignación de culpas y castigos requiere de un tacto lo suficientemente instruido (a veces por los duros golpes de la vida) para delimitar la fuerza de una conciencia moralista que muchas veces, abusando de su poder, pretende sobreponerse frente a cualquier error de un ser que como Fedra no decidió su destino. Teseo, Fedra e Hipólito se ven enredados en una trama lo suficientemente teñida por los deseos y las pasiones propias de lo humano, que se hace imposible juzgar en blanco o negro cualquiera de sus acciones. La conciencia moral escrupulosa se descubre truncada por una interacción sentimental y circunstancial que relativiza su pretensión de emitir un juicio condenatorio definitivo, al tiempo que demuestra la fragilidad del bien y la felicidad. La condición humana termina estando en las antípodas de la divina. No hay perfección moral que buscar, ni agentes totalmente culpables, ni pacientes absolutamente inocentes. La culpa se convierte en el signo central de una condición tremenda: la fragilidad humana.

\section{Franqueza, valía moral y fragilidad del juicio condenatorio}

En Electra (Eurípides, 1985), la parresía se presenta aunada a la deliberación moral. El debate entre Clitemnestra y Electra en torno a la asignación de responsabilidad y la evaluación de los actos de la madre y lo que la llevó a asesinar a su esposo y padre de la adolorida protagonista se convierte en una discusión sometida a la condición del franc-parler. Foucault resalta esta exigencia (2004, pp. 60-63) pues en el diálogo aparece tanto del lado de la madre como de la hija, la primera le dice a la otra: "Habla, si algo quieres decir, y replícame con libertad que tu padre no murió con justicia" (Eurípides, Electra, 1985, vv. 1049-1050). A lo cual Electra le responde: "Madre, recuerda las últimas palabras que has pronunciado concediéndome libertad para hablar" (vv. 1055-1056). La importancia de esta explicitación desde el comienzo del choque argumentativo señala un rasgo bien notorio de todo debate con peso realmente moral, a saber, la dureza de las verdades que hay que decir, y ello porque no se trata simplemente de describir hechos o acontecimientos sino de valorar el tipo de persona que se manifiesta a través de ellos. La acción entra así en un conflicto de interpretaciones porque es la misma persona, su carácter y su valía la que es puesta en cuestión en el juego incesante de atribución de culpas y cargas. Todo el discurso posterior de Electra se dedica a señalar la impureza de los motivos que su madre alega (v. 1060 y ss.), con lo cual de esposa y madre afectada pasa a convertirse en amante traidora y madre desalmada. Sin embargo, esta Electra de Eurípides también termina atormentada por la venganza contra la madre por más impía que esta resultaba a sus ojos. Junto a su hermano y cómplice de la ven- 
ganza, Orestes, lanza los últimos lamentos quejándose del acto cometido:

Orestes. - Yo puse el manto sobre mis ojos y di comienzo con la espada al sacrificio hundiéndola en el cuello de mi madre.

Electra. - $\mathrm{Y}$ yo te animaba al tiempo que ponía mano a la espada.

Coro. - Has cometido el más terrible crimen.

Antistrofa $4^{\mathrm{a}}$.

Orestes. - Toma, cubre los miembros de mi madre con el manto y cierra sus heridas. ¡En verdad alumbraste a tus propios asesinos!

Electra. - iVed cómo ponemos este manto sobre quien era amiga y a la vez no amiga! (vv. 1222-1231)

El remordimiento trasciende el orden de las justificaciones, el discurso se muestra insuficiente para apaciguar el tormento que proviene de la conciencia del acto reprochado. El reclamo mismo de uno de los hermanos de Clitemnestra, Cástor, precisa el punto alrededor del cual gravita toda la pena de los hijos matricidas: "Ella ha recibido su merecido, pero tú no has obrado con justicia" (v. 1245). El sufrimiento alcanza tanto a vencedores como a vencidos, a victimarios como a víctimas.

\section{Sed de venganza y obnubilación del juicio}

Orestes (Eurípides, 1998) también aparece como un ser totalmente abatido revolcándose en el dramatismo de su propio remordimiento:

Desde entonces (desde que dio muerte a su madre), aquejado por una feroz enfermedad, se consume el desgraciado
Orestes. Aquí yace tendido sobre el lecho y la sangre de su madre lo transporta vertiginosamente en ataques de locura. Pues no me atrevo a nombrar a las diosas (Euménides que rivalizan en aterrorizarlo). Este es ya el sexto día desde que murió mi madre a golpes de espada y su cuerpo quedó purificado por el fuego. Durante estos días no ha admitido alimentos por su garganta, no ha bañado su piel. Oculto bajo los mantos llora, cuando la enfermedad alivia su opresión y recobra la razón, pero otras veces salta del lecho y echa a correr, como un potro que huye del yugo (vv. 34-46).

De héroe vengador pasa a convertirse en hombre infame, la locura y sinrazón contrastan con la airada y segura justificación que otrora diera de sus actos. Su conciencia ya no es la guía segura de sus acciones sino la enfermedad que le corroe, "Menelao. — ¿Qué opresión sufres? ¿Qué enfermedad te destruye? Orestes. - La conciencia, porque sé que he cometido actos terribles" (vv. 395-396). Las palabras de su abuelo, Tindáreo, le reprochan haber actuado por fuera de la racionalidad de la ley y haberse dejado llevar por su sed de venganza:

Él (Orestes) habría debido entablar un proceso criminal, prosiguiendo una acción legal legítima, y expulsar del palacio a su madre. Habría mostrado su prudencia en la desgracia, se hubiera amparado en la ley y habría sido piadoso. Ahora en cambio ha incurrido en la misma fatalidad que su madre. Pues, aunque justamente la consideró perversa, él se ha hecho más perverso al matarla (vv. 500-506).

Llama la atención sin embargo que Orestes, en medio de la locura del arrepentimiento que le atormenta, saque fuerzas para articular un discurso autojustificador, cuyos argumentos centrales son: (a) la legítima defensa de la memoria 
paterna y (b) la necesaria ejemplificación para evitar que las mujeres se sientan tentadas a imitar a su madre (v. 545 y ss.). ¿Lucidez o ceguera? La solución o salida de la culpa en esta tragedia termina siendo entonces una evasión, un maníaco júbilo. En todo caso, la stultitia ataca nuevamente a Orestes y decide darle muerte a Helena, esposa de su pariente Menelao, por la negativa de este para apoyarlo ante el pueblo. En el impulso que Electra le da aparecen descritas las acciones que demeritan a Helena y hacen ver justificable su muerte:

Electra. - ¡Matadla, asesinadla, degolladla, hincadle los dobles puñales de doble filo con todo el impulso de vuestro brazo, a la que abandonó a su patria y a su marido, la que aniquiló a muchísimos griegos, que bajo la lanza murieron en la márgenes del río (vv. 1303-1306).

La indiferencia de Menelao frente a Orestes no basta para explicar el crimen contra su esposa, hace falta también que esta aparezca como un ser vil contra el cual cualquier bajeza está justificada. Y ciertamente la aparición de Apolo como deus ex machina no convence de lograr un final feliz (v. 1625 y ss.). El sentido del desenlace se pierde en el artificio de un dios que pretende recomponer las cosas para reinsertar un cierto orden en el caótico mundo de Orestes. Pero ¿significa esto que una vez Orestes ha adquirido la identidad de culpable y loco no puede resolverse a actuar de otro modo?, ¿es la culpa portadora de un estigma imborrable?, ¿o es simplemente el signo de una grieta profunda de la condición humana, a la vez moral e inmoral, noble e innoble, bondadosa y malvada? Se trata de una situación en la que ninguno de los dos hermanos ha quedado con el sentimiento de haber logrado un triunfo o cobrado justicia, quedan embargados solamente por tristeza y horror (cfr. Lesky, 2001, p. 315) y, más allá del estigma que les pueda quedar o de la intervención divina, se ven envueltos en el tormento de su propia contrición. No estamos pues ante la taxonomía moral rotunda de hombres buenos y malos sino ante el hecho incontestable de que "...en los conflictos del hombre contra el hombre, siempre nos encontramos con cierta humanidad y buenas razones en ambos lados" (Kaufmann, 1978, p. 223). Esta es una de las razones por las que se hace tan difícil precisar y asignar culpabilidad, pues si se trata de malas acciones cometidas por malas personas no se duda un instante, pero si se trata de acciones malas cometidas accidentalmente por hombres buenos, el dilema comienza. ¿Se trata entonces de una antropología pesimista? Si ello es así, el problema es de nuevo el fondo antropológico y ontológico del mal que subyace al asunto de una ética de la culpabilidad. Para evitar este círculo vicioso lo que hay que distinguir es la relación entre el sujeto y la acción y no ambas por separado. Con ello la asignación de culpabilidad está en función de una relación (entre el agente y su acción o entre el paciente y el padecimiento) y no en función de una entidad.

\section{Conciencia moral y alteridad del ex- ceso dionisíaco}

Quizás sea con el mito de Dioniso en Las Bacantes (Eurípides, 1998) donde Eurípides nos permite ver mejor la inmanencia de una tensión dramática en las tendencias humanas. No es ni siquiera la trascendencia de una posesión divina la que explica la terrible desmesura que puede realizar lo humano, es la inherencia de un daimon propio lo que actúa como fuerza acicateadora del exceso. Ahora bien, ¿lo que representa Dioniso y su culto es un contra-orden o es otro tipo de establishment?

El coro refleja bien, en su aspecto atractivo y repelente, la ambivalencia del dionisismo: su euforia festiva y su desafío a las civilizadas normas de la cordura. Lo que impulsa a tomar el tirso y hacerse bacante es el entusiasmo dionisíaco, que, como una forma de locura religiosa, de manía, puede ser bendición, pero también castigo... (De Cuenca y García, 1998, p. 329). 
¿Estamos entonces ante ese necesario ingrediente feliz para toda vida completa o frente al peligro del desbordamiento y del exceso? Esa euforia y demanda de entusiasmo que la vida se hace a sí misma debe suspender el afán moralista de evaluación y juicio. No se trata ya de una conciencia atormentada por la tarea de definir culpas y castigos, sino de la vida que se desborda en una celebración por continuar en el orden del mundo.

Es Penteo el defensor de los valores tradicionales desde el punto de vista de la moral griega, bien que la excesiva soberbia de su posición le haga incurrir en hýbris. Penteo es, como Hipólito, un héroe demasiado seguro de su moralidad, sin advertir la unilateralidad de su concepción hasta el momento de su muerte (p. 335).

¿Cómo es posible entonces que la moral pueda incurrir en transgresión? En el sentido precisamente de que solo una conciencia que haya pasado por la experiencia de lo otro y lo extraño, el exceso y el peligro, está en capacidad de comprender cabalmente las situaciones y vivencias catastróficas en las que cualquiera se puede ver inmerso. La conciencia aleccionada para la comprensión de la experiencia humana como complejidad de motivos, causas, factores, valores, antivalores, es una conciencia formada también en la escuela de Dioniso. La unilateralidad, la soberbia, el exceso de autoconfianza de una conciencia moralista termina aniquilando lo que de prudente y sabio pueda tener su juicio, y en ello reside su hýbris. El héroe que alardea de su virtud está, aún sin saberlo, expuesto a hacer el espectáculo de un arrogante moral y, en el patetismo de su ceguera, los demás se apartan de él por la testarudez y cerrazón de su conciencia para vislumbrar otras posibilidades, razones y motivos. Solo una conciencia instruida por la alteridad de su normatividad puede entender la necesidad de perdonar. Como dice Vernant:

En esta cultura griega en ciertos aspectos tan precisamente acotada, Dioniso desdibuja las fronteras. (...) En la medida en que están tan delimitadas las fronteras entre el hombre y la mujer, entre lo griego y lo bárbaro, entre los hombres y los dioses (entre el culpable y el inocente, entre el mal y el bien), en esa misma medida, se deja un sitio a la necesidad de hacer saltar, en ciertos momentos, el sistema (2002, p. 213).

No se trata pues de un sistema que absorbe la alteridad sino de un sistema que explota y se intenta recomponer, pero, en cada intento nuevo, deviene distinto. La nostalgia por el sistema siempre será, pues, apego a un pasado irrecuperable. Incluso su recuerdo se ve siempre amenazado por la ficción idealizadora que merodea a toda nostalgia.

Cuando Cadmo le dice a Tiresias que lo guíe hacia los rituales dionisíacos, lo llama "sabio" (Eurípides, Las Bacantes, 1998, vv. 185186) y no en el sentido de Penteo, el moralista, sino en el de una conciencia instruida por el lado paliativo de la fiesta y el vino (De Cuenca y García, 1998, p. 359, nota 25$)^{3}$. Esta reivindicación del lado constructivo de Dioniso nos recuerda la patología de la conciencia culpabilizadora, su terquedad y obtusa visión. Su mirada no busca más que lo que le sirve de material para el juicio condenatorio pero no aquello que lo haga matizar. Por ejemplo cuando, frente a Penteo, el mensajero llega a narrar los hechos del ritual que se está llevando a cabo por las mujeres en el monte, su primera preocupación es si puede hablar con toda franqueza (Eurípides, Las Bacantes, 1998, vv. 665-670), pues uno de sus temores es aparecer, ante ese juez moralista y por ello terrible, como otro de los culpables de tal desenfreno.

La veneración dionisíaca también permite valorar en su justo lugar el arte de vivir en comparación con el saber por el saber:

(Coro:) La ciencia de los sabios no es la sabiduría. Ni tampoco lo es el meditar sobre lo inhumano. ¡Breve es la vida! 
Por eso, ¿quién puede cosechar el presente si persigue lo infinito? Esas son actitudes, en mi opinión, de mortales enloquecidos (vv. 395-400).

La locura no es ya de quienes viven el ritual liberador de Dioniso sino de quienes le niegan sus beneficios, entre ellos, el elogio de una vida sencilla y feliz, cercana a la naturaleza y los ritmos de la vida (v. 420 y ss.) que nos recuerda "la fuerza verdadera de la naturaleza que es indiferente al bien o al mal" (Bowra, 1948, p. 94). No en vano Dioniso también es el dios de las máscaras pues los ritmos, tránsitos, declives, reveses de fortuna, logros, etcétera, propios de esa corta y compleja vida no hacen sino exigir la constante adaptación. Se trataría pues de una ética de la cotidianidad que, a riesgo de confundirse con la variabilidad incesante de las sensaciones, regula su aprehensión a través del filtro del principio productivo del dionisismo, a saber, la lógica de la felicidad, "esa vida serena de las alegrías cotidianas y el gozar 'día a día" (De Cuenca y García, 1998, p. 386, nota 56). Esta vivencia no reflexionada de la vida, ese dejar transcurrir se convierte en el complemento necesario de la hiperreflexión en la que puede caer la conciencia moral. Eso le hace saber Cadmo a su hija Ágave cuando le advierte que, por haber estado en trance, no se dio cuenta de que ella también ayudó a destrozar a su hijo Penteo: "Cadmo. — iAy! ¡Ay! ¡Cuando comprendáis lo que habéis hecho, sufriréis un tremendo dolor! Pero si hasta el fin os quedáis sin pausas en el estado en que estáis, sin ser felices, al menos parecerá que evitáis la desdicha" (Eurípides, Las Bacantes, 1998, vv. 1259-1263). Como bien lo resaltan De Cuenca y García, esa ignorancia que evita el sufrimiento se contrapone en Eurípides a la lucidez y la conciencia (1998, p. 401, nota 77). Esta, posterior a los hechos, confirma su carácter trágico.

“Ágave. - Y, nosotras, ¿de qué modo fuimos a parar allí?

Cadmo. - Estabais en delirio y toda la ciudad estaba poseída por Baco.
Ágave. -Dioniso nos destruyó. Ahora lo comprendo" (Eurípides, Las Bacantes, 1998, vv. 1294-1296).

Pero si la conciencia moral también es conciencia del dolor por la culpa y el remordimiento, el conocimiento se hace conditio sine qua non para la convivencia y la fundación de la ciudad. El famoso juego de inculpaciones y justificaciones - acusaciones y contraacusaciones, esto es, la pugna por la verdad y las tentaciones de engañar(se) - se complementa con el imperativo de conocer a los culpables para regular los controles y las penas.

El mismo Dioniso se presenta como el extraño que habita esta conciencia reflexiva: "Como dice M. Détienne, si este dios se presenta como Extranjero y Extraño, no es porque sea de procedencia exótica, 'es porque el dios tiene por vocación lo Extraño"” (De Cuenca y García, 1998, p. 335, nota 10). Lo fundamental sería no ubicar lo dionisíaco en el exterior sino ver la tragedia que nos ocupa como metáfora del espíritu humano, como metáfora de las fuerzas que luchan en la conciencia. Incluso la huída al monte como "uno de los elementos del ritual báquico" (p. 352, nota 15) es una forma de alejarse de la civilización y la regulación propias de la polis en búsqueda de la libertad para darles rienda suelta al delirio y la embriaguez, que se constituyen en una manera de tensionar la vida cívica. No es meramente que se huya a ese lugar carente de leyes y se permanezca allá, sino que el retorno de ese éxtasis reconstituye la vida regulada que implica lo colectivo a riesgo incluso de transformarla.

La culpabilidad se presenta entonces como manía de una conciencia moral arrogante si no es relativizada en el conflicto de interpretaciones y justificaciones de toda deliberación moral. La ambivalencia e inseguridad que con esa relativización gana el veredicto termina siendo la garantía de la posibilidad de la reapertura del juicio y la reivindicación de la justicia. Pero si esto también es una dimensión más allá 
de la moralidad, puede considerarse que lo dionisíaco representa una faceta de la vida que no tiene propiamente ninguna ética o que su ética no consiste en la moral de la "cordura, racionalidad y represión colectiva" (p. 337). Ahora, si uno de los ejes del rito a Dioniso lo constituye la fiesta, quizás esta se integra al orden social a la manera de tensa complementación que permite gastar la energía acumulada en el tiempo del trabajo y la regulación (cfr. Bataille, 2000). La sacudida dionisíaca correspondería de este modo al desfogue de una vida regida por la monotonía del moralismo y el control ${ }^{4}$, aunque no hay que olvidar que en la contemporaneidad este desfogue también ha sido subsumido en la lógica de la mercancía ${ }^{5}$.

\section{Conclusión}

A partir de las tragedias de Eurípides la línea entre bien y mal, justicia y venganza, inocencia y culpabilidad, tranquilidad y remordimiento, defensa y acusación, interés personal y egoísmo, es muy delgada. La arrogancia moral deviene patetismo de una conciencia obtusa y empecinada en la valía de sus rígidos principios, segura de la infalibilidad no solo de su constitución ontológica sino también de su capacidad de realización práctica. Con ello, la conciencia moral se convierte en tribunal indiferente ante los incidentes de la acción, el dolor y la perenne posibilidad de transgresión, manía y maldad que constantemente amenazan la propia existencia. Así pues no solo estamos frente a unos textos que muestran la orfandad humana respecto a los dioses sino también la falibilidad de su condición pasional y la lucha entre sabiduría y arrogancia que constituye los dilemas morales. Los artilugios del azar se presentan como una fuerza más en el juego intersubjetivo y social de la moral in situ. Este carácter pragmático e interesado de la moralidad, su faceta egoísta y en permanente tensión con las exigencias institucionales, las peripecias del amor y el reclamo de solidaridad propia de la conminación hacen de la ética un ejercicio labrado en la dimensión de lo fronterizo, lo vulnerable y muchas veces amenazado por lo caótico. Un ejercicio enmarcado en el conflicto de interpretaciones de las leyes y los hechos, las imputaciones y exculpaciones, los discursos y la acción, los poderes y los anhelos, las angustias y las sensibilidades, el contexto y los proyectos (cf. Benevides, s/a, p. 7). Algo con lo cual la conciencia deja de ser muchas veces la guía segura de los juicios y el comportamiento para convertirse en tormento, enfermedad y locura. Ambigüedad política y moral de los veredictos y castigos que no solo es patrimonio de la antigüedad sino que alcanza los debates y problemas morales de la modernidad (cf. Schuld, 2000, p. 19) y que logra poner en cuestión no solamente las acciones evaluadas sino también la valoración de las personas y los resultados mismos de los juicios. En esta circunstancia, la enseñanza positiva del dionisismo consiste precisamente en abrazar la fuerza proveniente de la alegría vital y el vínculo con la falibilidad de la condición humana en una ética distinta a las pretensiones de una moral del deber obsesionada con la homogeneización, la hiperreflexión y el control. Una ética del deseo y del placer, de la vida feliz que también reclama el derecho a la diferencia y a la interacción no dominadora. De este modo y si la desesperanza en lo político ronda todas las tragedias de Eurípides (De Cuenca y García, Fenicias, 1998, p. 80), podría proponerse la hipótesis de Eurípides: trágico de lo político, ya que, en efecto, ante la distancia de los dioses y la ambiciosa naturaleza humana que casi todo lo echa a perder en el vaivén conflictivo de las pasiones y egoísmos pues "el destino que aniquila la casa de Edipo se halla fatalmente ínsito en los propios caracteres" (p. 87) — dado que no hay ya dioses a quienes acudir para que se inmiscuyan en la salvación de los hombres, ni regímenes lo suficientemente justos para regular la convivencia social, con lo cual la tragedia no reposa solamente en la exterioridad de un designio divino o en la trascendencia de un azar caprichoso-, tal vez quede la tarea de reconstruirse a sí mismo como proyecto intransferible, como tarea ética, como obra y cuidado para una sabiduría aleccionada por lo trágico, como conciencia de la 
falibilidad no obstante responsable y creadora que constituye la existencia de los hombres en la reapertura de sus certezas, exigencia ínsita a una vida jugada también en la indeterminación de la libertad y la contingencia.

\section{Notas}

${ }^{1}$ Las referencias de las tragedias se harán con los números de los versos (vv.) y no con los de las páginas.

2 "Cuando Hipólito (...), rehúsa fría y bruscamente el saludo a Afrodita, comprendemos que su orgullosa castidad significa al mismo tiempo una hybris, una insolencia o arrogancia al negar a uno de los grandes poderes de la vida" (Lesky, 2001, p. 284).

${ }^{3} \mathrm{Al}$ respecto es muy clarificadora la explicación de Vernant: "El dionisismo no representa en absoluto un elemento exterior, marginal en la civilización griega. Es, por el contrario, un elemento central, pero que va en una dirección diferente, en el interior del sistema. Yo creo que no existe civilización que sea perfectamente coherente, cuya lógica tenga una sola dimensión. Sí, el dionisismo toma el sentido inverso de ciertas cosas, pero eso forma también parte del sistema" (2002, p. 209). Y, más adelante, "Las Bacantes reflexionan sobre el personaje de Dioniso: señor de la tragedia, al que no se puede abordar sino aceptando cambiar la visión de las cosas, aceptando transformarse en otro y aceptando la idea de que todas las categorías que nos parecen bien definidas pueden ser trastornadas" (p. 216). La identidad se convierte de este modo en movilidad del ser, y la diferencia, lo múltiple, la cara inocente del culpable como la cara culpable de aquel se revelan como facetas también presentes en esa primera identidad segura de sí misma. La arrogancia del inocente se verá minada por esta posibilidad que también le habita: ser culpable de la indiferencia ante el doliente de una transgresión.

${ }^{4}$ En este mismo sentido se pronuncian Vernant y Vidal-Naquet cuando plantean que "al igual que en muchas otras sociedades el orden, para consolidarse, necesita ser periódicamente controvertido, trastornado durante esos días de carnaval en los que reina la inversión..." (2002, p. 40).

${ }^{5}$ Cfr. la discusión en torno a las hipótesis represiva y discursiva en la Historia de la sexualidad 1 (Foucault, 2005).

\section{Referencias}

Bataille, G. (2000). El erotismo. Barcelona: Tusquets.

Benevides Valle, L. (s/a) (2012, 14 de junio). Le rapport psychiatrie - justice chez Foucault et la conception des hybrides chez Latour: quelques rapprochements possible. Recuperado de http://www.europhilosophie.eu/recherche/IMG/pdf/Foucault_et_Latour.pdf

Bowra, C. M. (1948). La tragedia ática. En Historia de la literatura griega (pp. 61-96). México: Fondo de Cultura Económica.

Castoriadis, C. (2006). Lo que hace a Grecia. 1. De Homero a Heráclito. Argentina: Fondo de Cultura Económica.

De Cuenca y Prado, Luis Alberto y García Gual, C. (1998). Traducción, introducciones y notas. En Eurípides. Tragedias III (Helena, Fenicias, Orestes, Ifigenia en Áulide, Bacantes, Reso). Madrid: Gredos.

Eurípides. (1985). Tragedias II (Suplicantes, Heracles, Ion, Las troyanas, Electra, Ifigenia entre los tauros). José Luis Calvo Martínez (Trad., introducciones y notas). Madrid: Gredos.

Eurípides. (1998). Tragedias III (Helena, Fenicias, Orestes, Ifigenia en Áulide, Bacantes, Reso). Carlos García Gual y Luis 
Alberto de Cuenca y Prado (Trad., introducciones y notas). Madrid: Gredos.

Eurípides. (1991). Tragedias I (El cíclope, Alcestis, Medea, Los heráclidas, Hipólito, Andrómaca, Hécuba). Alberto Medina González y Juan Antonio López Férez (Trad. y notas). Madrid: Gredos.

Foucault, M. (1994). Le pouvoir, une bête magnifique. En Dits et écrits III (19761979), 212, pp. 368-382. Daniel Defert et François Ewald avec la collaboration de Jacques Lagrange (eds.). París: Gallimard.

Foucault, M. (1994a). À propos de la généalogie de l'éthique: un aperçu du travail en cours. En Dits et écrits IV (1980-1988), 326, (pp. 383-411). Daniel Defert et François Ewald avec la collaboration de Jacques Lagrange (eds.). París: Gallimard.

Foucault, M. (2004). Discurso y verdad en la antigua Grecia. Barcelona: Paidós.

Foucault, M. (2005). Historia de la sexualidad, 1. La voluntad de saber. Madrid: Siglo XXI.

Jankélévitch, V. (1987). La mala conciencia. México: Fondo de Cultura Económica.
Kaufmann, W. (1978). Tragedia y filosofia. Barcelona: Seix Barral.

Lesky, A. (2001). La tragedia griega. Barcelona: El Acantilado.

Medina González, A. y López Férez, J. A. (1991). Introducción general a Eurípides (pp. 7-97). En Eurípides. Tragedias I (El cíclope, Alcestis, Medea, Los heráclidas, Hipólito, Andrómaca, Hécuba). Alberto Medina González y Juan Antonio López Férez (trads.). Madrid: Gredos.

Pewzner, E. (1999). El hombre culpable. La locura y la falta en Occidente. Mexico: Fondo de Cultura Económica.

Ricoeur, P. (2004). Finitud y culpabilidad. Madrid: Trotta.

Schuld, J. J. (2000, enero). Augustine, Foucault, and the Politics of Imperfection En The Journal of Religion, 80(1), (pp. 1-22).

Vernant, J. P. (2002). Acerca de lo trágico. En Entre mito y política (pp. 208-236). México: Fondo de Cultura Económica.

Vernant, J. P. y Vidal-Naquet, P. (2002). Mito y tragedia en la Grecia antigua II. Barcelona: Paidós. 
